\title{
INSTITUTO MOREIRA SALLES
}

\section{Visa à promoção e ao desenvolvimento da cultura brasileira e prioriza as atividades ligadas à fotografia, à literatura e ao cinema}

O Instituto Moreira Salles (IMS), criado em 1989 e mantido pelo Unibanco, não tem fins lucrativos e conta com o apoio das Leis de Incentivo à Cultura do Ministério da Cultura. Fundou, em agosto de 1992, seu primeiro centro cultural, na cidade de Poços de Caldas, MG. De lá para cá inaugurou mais dois centros culturais - em Belo Horizonte e São Paulo - preparando, ainda para este ano, inauguração no Rio de Janeiro. É responsável pelo patrocínio do Espaço Unibanco de Cinema, que conta com dez cinemas localizados em São Paulo, Rio de Janeiro, Belo Horizonte e Porto Alegre. Edita semestralmente os Cadernos de Literatura Brasileira, além de livros, catálogos e programas que acompanham exposições, recitais, cursos, seminários, oficinas, palestras e conferências.

O IMS-Poços de Caldas, além de promover exposições, cursos, concertos e lançamentos de livros, desenvolve projetos de arte-educação para o público infantil e outros voltados para o público jovem, adulto e de terceira idade. Funciona no centenário

\section{A AUTORA}

\section{Jandira Queiroz}

Assistente editorial da revista Comunicação \& Educação.
Chalé Cristiano Osório, por onde já passaram 134 mil pessoas. O IMS-São Paulo, inaugurado em janeiro de 1996, funciona como centro de recepção e manutenção de arquivos históricos privados, bibliotecas, acervos fotográficos, iconográficos e documentais, preocupando-se com a preservação da memória brasileira. O IMS-Belo Horizonte funciona, desde janeiro de 1997, num prédio no centro da cidade, construído em 1925 e tombado pelo Patrimônio Histórico em 1994. O IMS-Rio, antes mesmo de ser inaugurado, já conta com a biblioteca de Otto Lara Resende, doada por sua família.

O acervo fotográfico do Instituto Moreira Salles, reunido desde 1995, contém mais de 10 mil imagens de várias regiões do país, sendo os registros mais importantes os das cidades do Rio de Janeiro e de São Paulo. As imagens que revelam as cidades a partir de meados do século XIX são assinadas por pioneiros como Marc Ferrez, George Leuzinger, Augusto Stahl, Juan Gutierrez, Vicenzo Pastore, Hildegard Rosenthal, Claude Lévi-Strauss e, mais recentemente, Juca Martins. Essa coleção encontra-se em fase de identificação e catalogação e estará, em breve, aberta ao público. 


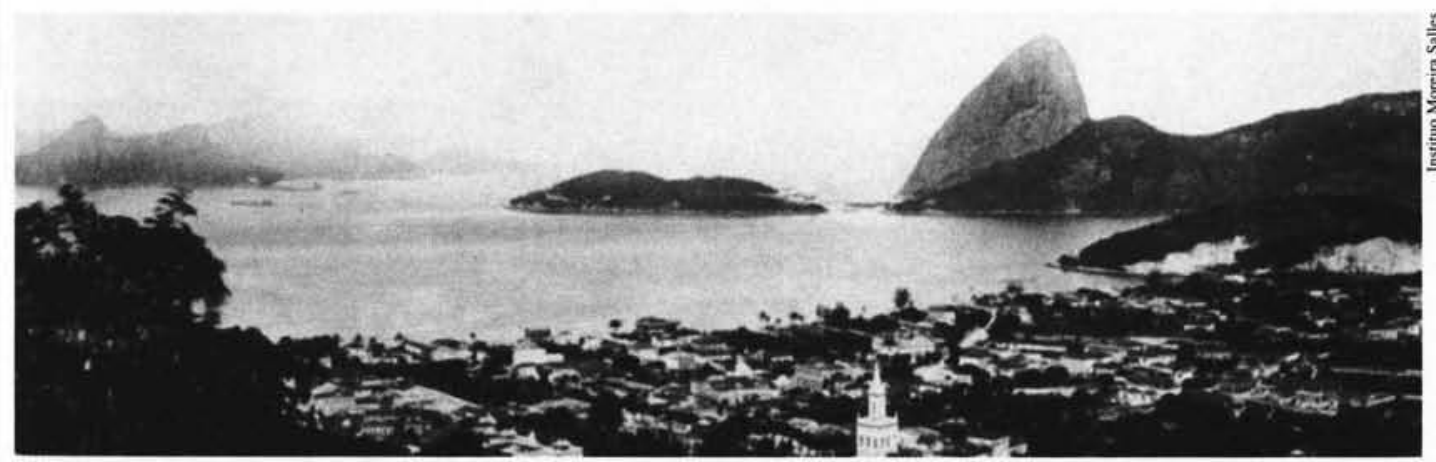

Foto de Marc Ferrez, panorâmica Baía de Guanabara, Rio de Janeiro, 1890.

A revista semestral Cadernos de Literatura Brasileira trata, em cada edição, da vida e da obra de um autor nacional. Lançada em março de 1996, com um número dedicado ao poeta pernambucano João Cabral de Melo Neto, a revista vem dando prioridade aos escritores vivos, trazendo aos leitores material inédito como originais, depoimentos e entrevista, dando especial atenção à edição fotográfica. Já foram publicadas edições sobre Raduan Nassar (set./96), Jorge Amado (mar./97), Rachel de Queiroz (set./97) e Lygia Fagundes Telles (mar./98). Esta última traz depoimento de José Saramago, ensaio de José Paulo Paes, além de três contos inéditos de Lygia Fagundes Telles. O número mais recente é dedicado ao poeta maranhense Ferreira Gullar, com depoimento de Dias Gomes e ensaio de Alcides Villaça. Os Cadernos de Literatura Brasileira estão disponíveis para venda nos centros culturais do IMS e nas livrarias comerciais.

\section{VALORIZAÇÃO \\ DA CULTURA BRASILEIRA}

Em sua proposta de valorização do autor brasileiro, o IMS-São Paulo deu início, em abril de 1997 , ao projeto $O$ escritor por ele mesmo. Nesta atividade os escritores falam de sua vida e lêem trechos de seus livros. Já participaram dos encontros Inácio de Loyola Brandão, Lygia Fagundes Telles, Luís Fernando Veríssimo, João Gilberto Noll, Ana Miranda, José Paulo Paes, Fernando Gabeira, Roberto Drummond (em Belo Horizonte), Carlos Heitor Cony, Ivan Ângelo e Ruth Rocha.

Os dez cinemas do Espaço Unibanco (São Paulo, Rio de Janeiro, Porto Alegre e Belo Horizonte) estão, desde 1995, sob a orientação do Instituto Moreira Salles, num total de 25 salas de projeção com capacidade para cerca de 4 mil pessoas.

O IMS preocupa-se com a produção cinematográfica nacional, e tem colaborado para que o Unibanco se destaque como patrocinador dos longas-metragens produzidos no Brasil.

O IMS-Poços de Caldas conta com um Vídeo-Cineclube, que apresenta duas sessões semanais, sempre precedidas por comentários de um crítico de cinema. Aos domingos, tem uma programação voltada ao público da terceira idade, com a exibição dos clássicos do cinema internacional, grandes diretores e artistas e de diversos gêneros. Às quintas-feiras apresenta obras clássicas e modernas, visando a um público mais heterogêneo. Organiza, ainda, o Festival da Juventude, realizado no período das férias escolares, nos meses de janeiro e ju- 


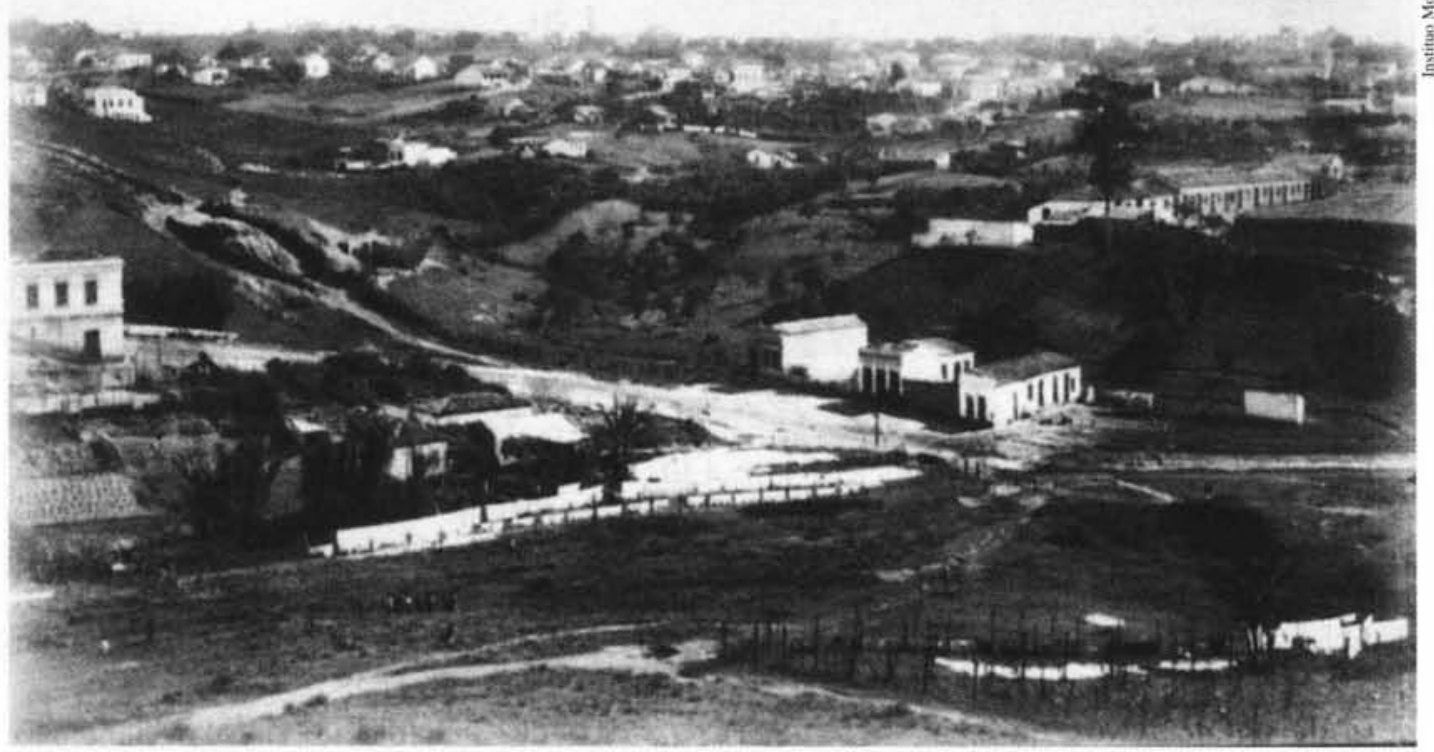

Foto de Vicenzo Pastore, panorâmica do Vale do Anhangabaú, no início deste século.

lho, com uma programação voltada para os jovens, incluindo exibição de vídeos musicais com os principais ídolos do rock e da música pop, além de filmes de grande sucesso de bilheteria.

Encontramos, também, entre as atividades do Instituto Moreira Salles recitais, cursos e oficinas de arte promovidos mensalmente, privilegiando solistas e grupos de pequena formação, com repertório de música erudita, jazz e música popular brasileira. São, ainda, realizados cursos de História da Música Erudita Brasileira e História da Arte. As oficinas de arte, geralmente de desenho e pintura, acontecem com frequiência no centro cultural de Poços de Caldas, direcionadas a estudantes, através de aulas práticas em ateliês e com o apoio de workshops de conceituados artistas plásticos. Em todos os seus centros culturais o IMS desenvolve programas de arte-educação, dos quais participam os Espaços Unibanco de Cinema, com visitas monitoradas a exposições e ati- vidades artísticas relacionadas aos temas das mostras. Todas as atividades do Instituto Moreira Salles chegam ao público gratuitamente.

\section{CONTATOS}

SITE: http://www.ims.com.br

E-MAIL: ims@nutecnet.com.br

\section{IMS-São Paulo}

Rua Piauí, $844-1^{\circ}$ andar

CEP 01241-000 - São Paulo-SP

Tel./fax: (011) 825-2560

Horário de funcionamento: de terças às sextas-feiras, das 13 às $20 \mathrm{~h}$, sábados e domingos, das 13 às $18 \mathrm{~h}$.

\section{IMS-Poços de Caldas}

Rua Teresópolis, 90 - CEP 37701-058

Poços de Caldas-MG

Tel./fax: (035) 722-2776

Horário de funcionamento: de terças-feiras a domingos, das 14 às $18 \mathrm{~h}$. 


\section{IMS-Belo Horizonte}

Av. Afonso Pena, 737 - Centro

CEP 30130-002 - Belo Horizonte-MG

Tels.: (031) 219.5281 / 5282 / 5283

Fax: (031) 219.5284

Horário de funcionamento: de terças

a domingos, das 13 às $18 \mathrm{~h} 30$.

\section{IMS-Rio de Janeiro}

Rua Marquês de São Vicente, 476 - Gávea

Rio de Janeiro-RJ. (A ser inaugurado.)

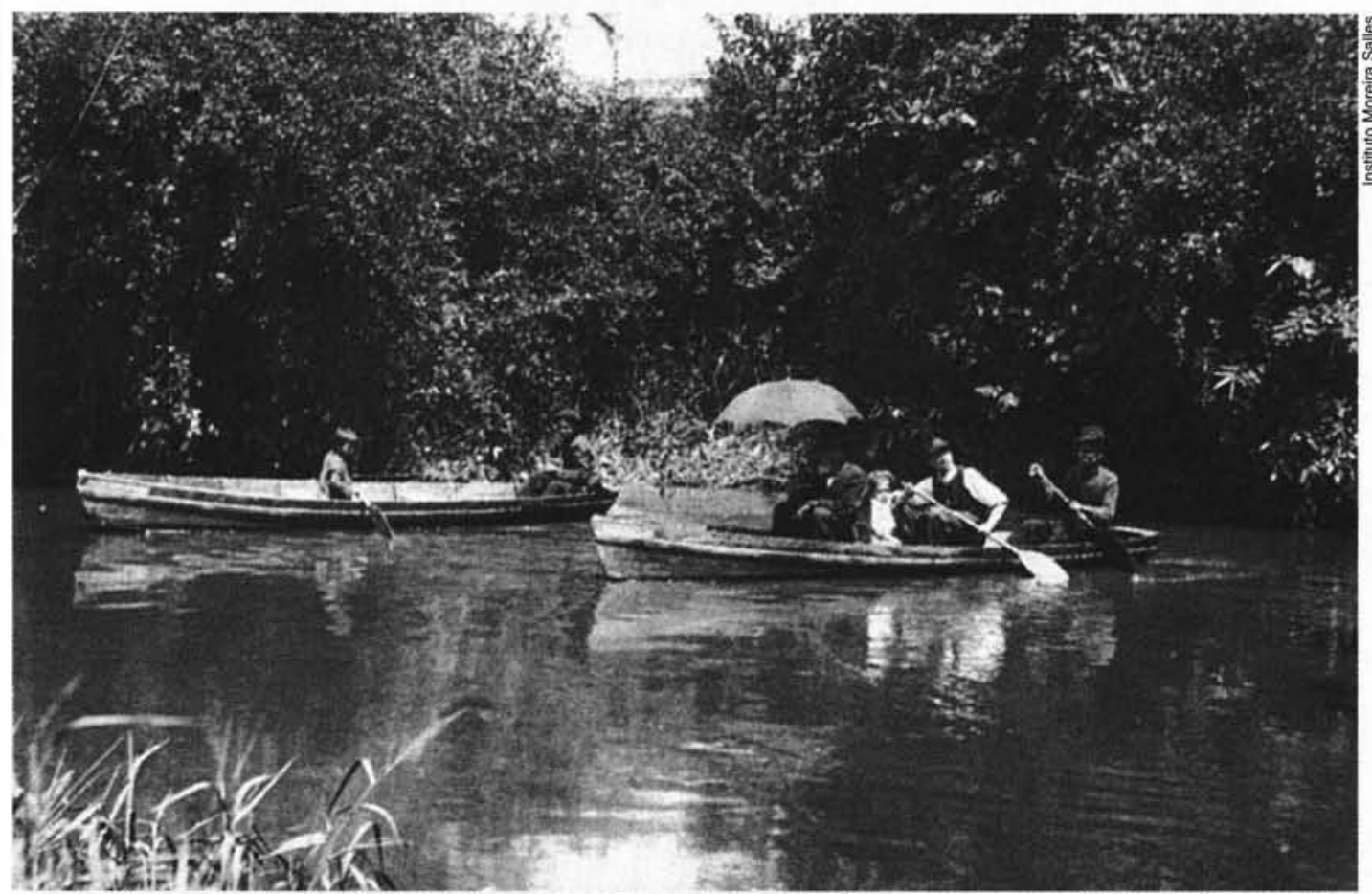

Foto de Vicenzo Pastore, o Rio Tamanduateí, em São Paulo era uma via de transporte, utilizada pela população.

Resumo: O Instituto Moreira Salles, criado em 1989 e mantido pelo Unibanco, incentiva atividades nas áreas de fotografia, literatura, cinema, cursos e oficinas de arte. Funciona como ponto de recepção e manutenção de arquivos históricos privados, bibliotecas, além de acervos fotográficos, iconográficos e documentais. Tem como objetivo a promoção da cultura nacional e suas sedes estão localizadas nas cidades de Poços de Caldas (MG), Belo Horizonte (MG), São Paulo (SP), Rio de Janeiro (RJ) e Porto Alegre (RS).

Palavras-chave: Instituto Moreira Salles, arteeducação, cinema, literatura, fotografia, cultura brasileira
Abstract: The Instituto Moreira Salles, established in 1989 and maintained by Unibanco, promotes activities in the areas of photography, literature, cinema, art courses and workshops. It works as a place for the reception and maintenance of private historical archives, and libraries, over and beyond as a photographic, iconographic and documentation collection. It aims at promoting national culture and its headquarters are located at Poços de Caldas (MG), Belo Horizonte (MG), São Paulo (SP), Rio de Janeiro (RJ) and Porto Alegre (RS).

Key words: Instituto Moreira Sales, arts, literature, photography, Brazilian culture 